ISSN Print : 1411 -951 X, ISSN Online : 2503-1716

Jurnal Ergonomi Indonesia

(The Indonesian Journal of Ergonomic)

Vol 4., No.1 : 1 Januari - Juni 2018

\title{
PENERAPAN CERVICAL STABILIZATION MELALUI ACTIVE EXERCISE MENINGKATKAN KEMAMPUAN FUNGSIONAL DAN PRODUKTIVITAS KERJA PENENUN ENDEK DI INDUSTRI TENUN IKAT DENPASAR
}

${ }^{1}$ Enny Fauziah, ${ }^{2}$ I Dewa Putu Sutjana, ${ }^{3}$ Luh Made Indah Sri Handari A, ${ }^{4}$ Ketut Tirtayasa, ${ }^{5}$ I Made Sutajaya, 6.Putu Gede Ery Suardana

${ }^{1}$ Mahasiswa Program Studi Magister Ergonomi Fisiologi Kerja Universitas Udayana

${ }^{2}$ Staff Dosen Program Studi Kesehatan dan Keselamatan Kerja Institut Ilmu Ksehatan Medika Persada Bali

${ }^{3}$ Staff Dosen Program Studi Magister Ergonomi Fisiologi Kerja Universitas Udayana

${ }^{4}$ Staff Dosen Program Studi Magister Ergonomi Fisiologi Kerja Universitas Udayana

${ }^{5}$ Staff Dosen Program Studi Biologi Universitas Pendidikan Ganesha

${ }^{6}$ Staff Dosen Program Studi Arsitektur Universitas Dwijendra

\section{1ennyfauziah@yahoo.co.id}

\begin{abstract}
ABSTRAK
Karakteristik menenun dilakukan dengan posisi duduk di kursi di depan alat tenun. Posisi duduk selama \pm 8 kerja, gerakan monoton, bahu sedikit terangkat, menyebabkan pekerja menyeimbangkan posisi tubuh. Sikap kerja demikian menyebabkan kontraksi statis pada otot bahu dan leher. Penelitian ini bertujuan untuk menunjukkan bahwa penerapan cervical stabilization melalui active exercise setiap 2 jam setelah bekerja meningkatkan kemampuan fungsional dilihat dari penurunan keluhan muskuloskeletal, kelelahan, peningkatan neck disability index dan produktivitas pada penenun di industri tenun ikat.

Penelitian ini merupakan eksperimental, dengan rancangan sama subjek. Periode 1 subjek tidak diberi perlakuan yaitu menenun seperti biasa. Periode 2 subjek diberi perlakuan dengan penerapan cervical stabilization melalui active exercise setiap 2 jam setelah bekerja. Washing out period dan adaptasi diberikan di antara kedua tahap. Keluhan muskuloskeletal diukur dengan kuesioner Nordic Body Map, kelelahan kerja dengan 30 item of rating scale, kemampuan fungsional leher diukur dengan neck disability index dan produktivitas berdasarkan perbandingan output dan input. Analisis data diperoleh dengan analisis deskriptif dan uji normalitas dengan ShapiroWilk, data berdistribusi normal dianalisis menggunakan uji t-paired, sedangkan data berdistribusi tidak normal dianalisis menggunakan uji Wilcoxon.

Penelitian ini menunjukkan bahwa penerapan cervical stabilization melalui active exercise meningkatkan kemampuan fungsional dilihat dari penurunan keluhan muskuloskeletal 17,05\%, kelelahan 19,78\%, peningkatan neck disability index 15,13\% dan produktivitas $66,67 \%$.

Dapat disimpulkan bahwa penerapan cervical stabilization melalui active exercise meningkatkan kemampuan fungsional dilihat dari keluhan muskuloskeletal, kelelahan kerja, neck disability index dan produktivitas kerja. Sehingga disarankan untuk diterapkan pada penenun di industri tenun ikat, untuk meningkatkan kemampuan fungsional pekerja.
\end{abstract}

Kata Kunci: Cervical Stabilization, Active Exercise, Kemampuan Fungsional, Produktivitas 
ISSN Print : 1411 -951 X, ISSN Online : 2503-1716

Jurnal Ergonomi Indonesia

(The Indonesian Journal of Ergonomic)

Vol 4., No.1 : 1 Januari - Juni 2018

\section{ABSTRACT \\ APPLICATION OF CERVICAL STABILIZATION THROUGH ACTIVE EXERCISE INCREASE FUNCTIONAL ABILITY AND WORK PRODUCTIVITY AMONG WORKERS IN DENPASAR WEAVING INDUSTRY}

Characteristics of weaver was done by sitting on a chair in front of the loom. Sitting position for \pm 8 working hours, monotonous movement, shoulders slightly raised, causing workers to balance body position. Work posture cause a static contraction to the shoulder and neck muscles. This study aims to show that the application of cervical stabilization through active exercise every 2 hours after work increase functional ability seen from decreasing musculoskeletal complaints, fatigue, increasing neck disability index and productivity among workers in weaving industry.

This experimental study has been done, with treatment by subject design. Period 1 subject is not treated ie weaving as usual. Period 2 subjects were treated with the application of cervical stabilization through active exercise every 2 hours after work. Between the two stages, washing out period and adaptation. Musculoskeletal complaints were measured by Nordic Body Map questionnaire, work fatigue with 30 item of rating scale, neck functional ability measured with neck disability index and productivity based on output and input ratio.

Analysis of the collected data is started with the descriptive analysis and the normality data tested using Shapiro-Wilk. Further, the data that has normal distribution are analyzed using t-paired and the data that has not a normal distribution are analyzed using Wilcoxon test. This study show that the application of cervical stabilization through active exercise increase functional ability seen from decreasing of musculoskeletal complaint $17.05 \%$, fatigue $19.78 \%$, increasing of neck disability index $15.13 \%$ and productivity $66.67 \%$.

It can be concluded that the application of cervical stabilization through active exercise increase functional ability seen from musculoskeletal complaints, work fatigue, neck disability index and work productivity. So it is suggested to apply to weavers in the weaving industry, to increase the functional ability of workers.

Keywords: Cervical Stabilization, Active Exercise, Functional Ability, Productivity 


\section{Jurnal Ergonomi Indonesia}

\section{(The Indonesian Journal of Ergonomic)}

\section{PENDAHULUAN}

Indonesia dikenal sebagai penghasil kerajinan tangan yang mampu bersaing di pasar dunia. Hasil produksi tersebut merupakan barang ekspor Indonesia. Salah satu produksi barang ekspor hasil kerajinan tangan yang mempunyai daya jual tinggi ialah kain tenun. Industri kerajinan tenun sangat berperan di sektor ekonomi dan pariwisata.

Industri kain tenun tradisional merupakan warisan budaya yang masih diminati oleh sebagian besar masyarakat Indonesia. Tenun tersebut diwariskan secara turun temurun dari generasi ke generasi secara tradisional. Hal tersebut dapat dibuktikan dengan adanya relief pada umpak batu yang menggambarkan seorang wanita sedang menenun (Suwati, 2007).

Salah satu kain tenun yang terkenal di Indonesia adalah kain tenun ikat endek khas Bali. Penggunaan kain endek berbeda-beda sesuai motifnya. Motif dengan nuansa alam, biasa digunakan untuk kegiatan sosial atau kegiatan sehari-hari. Sehingga, motif tersebut lebih banyak berkembang di masyarakat (Adnyani, 2013).

Salah satu hasil kerajinan tenun ikat endek adalah hasil produksi Bali Sekar Jepun yang terletak di Kecamatan Denpasar Timur Kota Denpasar. Hasil kerajinan tenun endek berupa bahan (kain) yang dibuat dari benang (kapas, sutera, dan sebagainya), yang terjadi karena adanya persilangan benang lusi dengan benang pakan. Karakteristik pekerjaan penenun dilakukan dengan posisi duduk di kursi di depan alat tenun. Sikap kerja demikian menyebabkan kontraksi otot statis pada otot-otot bahu dan leher selama \pm 8 jam kerja. Kontraksi statis selama kerja menyebabkan aliran darah pada otot menurun dan menimbulkan penumpukan asam laktat sehingga meningkatkan rasa nyeri dan menimbulkan kelelahan serta menurunkan kemampuan fungsional.

Keluhan berupa nyeri otot, pegal di sekitar leher, bahu, dan kesemutan pada lengan biasanya lebih dikenal dengan myofascial pain syndrome. Sindroma miofasial ialah kumpulan gejala dan tanda dari satu atau beberapa titik picu (trigger points) dengan ciri berupa nyeri otot kronis dengan adanya peningkatan sensitivitas terhadap tekanan (Werenski, 2011).

Keluhan tersebut didukung dengan posisi kerja duduk \pm 8 jam per hari mulai pukul 08.00 s.d. 17.00 WITA dan waktu istirahat selama 1 jam yaitu pada pukul 12.00 s.d. 13.00 WITA selama tujuh hari kerja tanpa hari libur di hari Minggu. Berdasarkan hasil wawancara kepada enam orang penenun tenun ikat endek diketahui bahwa dalam satu hari pekerja mampu menyelesaikan 2,5 meter kain tenun ikat endek dengan upah Rp.15.000,00 per meter. Saat penenun ikat endek menenun terjadi gerakan berulang atau repetitif dan statis.

Hasil studi pendahuluan terhadap enam orang penenun tenun ikat endek diketahui tingkat keluhan muskuloskeletal, 5 dari 6 orang penenun mengeluhkan pada otot leher bagian bawah, dan 1 orang mengeluhkan pada bahu kiri dan kanan. Berbagai permasalahan tersebut yang menjadi masalah utama dan perlu dibenahi melalui pendekatan partisipatori dengan para penenun tenun ikat endek dan pemilik industri tenun ikat endek tersebut. Pemecahan masalah dengan cara perbaikan organisasi kerja berupa penerapan dan pemberian istirahat aktif pada pukul 10.00 dan 15.00 WITA dengan durasi 10 menit berupa penerapan cervical stabilization melalui active exercise. Melalui pendekatan partisipatori (participatory approach), seluruh komponen organisasi akan merasa terlibat berkontribusi dan bertanggung jawab terhadap perbaikan yang dilakukan (Manuaba, 2006).

Bentuk terapi latihan yang dapat diberikan berupa cervical stabilization melalui active exercise yang berguna memberikan stabilitas dari tulang servikal agar dapat tegak dan mempertahankan terhadap berbagai tekanan serta untuk memberikan dasar yang stabil sehingga otot-otot yang menstabilisasi leher dapat melakukan fungsi secara efisien dan dapat mencegah terjadinya cedera berulang dan 


\section{Jurnal Ergonomi Indonesia}

\section{(The Indonesian Journal of Ergonomic)}

juga untuk mengaktifkan otot-otot deep cervical seperti rectus capitis anterior dan lateralis serta longus colli (Kisner dan Colby, 2012).

Latihan stabilisasi ini dilakukan 2 kali sehari, 3 kali seminggu, selama 4 minggu dengan durasi latihan 10 menit dapat menurunkan risiko keluhan muskuloskeletal dan meningkatkan aktivitas fungsional. Menurut penelitian sebelumnya yang dilakukan oleh Kaka dkk. (2015) diberikan Cervical Stabilization terjadi penurunan keluhan muskuloskeletal pada minggu ke-4.

Berdasarkan uraian di atas maka dilakukan penelitian terhadap penenun tenun ikat endek melalui intervensi ergonomi berupa penerapan cervical stabilization melalui active exercise dan perbaikan organisasi kerja sebagai upaya mengatasi berbagai permasalahan yang muncul. Dengan intervensi tersebut diharapkan dapat meningkatkan kemampuan fungsional yang dilihat dari penurunan keluhan muskuloskeletal, kelelahan kerja, peningkatkan neck disability index dan produktivitas kerja penenun endek di industri tenun ikat di Denpasar.

\section{METODE PENELITIAN \\ Rancangan Penelitian}

Penelitian ini merupakan penelitian eksperimental dengan menggunakan rancangan sama subjek (treatment by subject design).

\section{Populasi dan Sampel}

Populasi target dalam penelitian ini adalah penenun di Denpasar, sedangkan populasi terjangkau dalam penelitian ini adalah penenun sekar jepun yang berjenis kelamin perempuan sebanyak 12 orang. Sampel diambil menggunakan teknik total sampel.

\section{Variabel dan Instrumen Penelitian}

1. Penerapan cervical stabilization melalui active exercise merupakan bentuk gerakan latihan yang berguna memberikan stabilitas dari tulang servikal agar leher dapat melakukan fungsi secara efisien dan dapat mencegah terjadinya cedera berulang. Latihan ini terdiri dari 5 gerakan yaitu chin tuck (neck retraction), cervical extension, shoulder shrugs, shoulder rolls, dan scapular retraction. Dosis latihan ini dengan 15 repetisi tahanan 2 detik, 1 set, dan dengan frekuensi $3 \mathrm{x}$ seminggu. Total lama latihan 10 menit dilakukan pada pukul 10.00 dan 15.00 WITA, latihan ini dilakukan 3 kali seminggu selama 4 minggu yaitu pada hari selasa, kamis, dan sabtu.

2. Perbaikan Organisasi Kerja dengan penerapan cervical stabilization melalui active exercise setiap setelah 2 jam bekerja yaitu pada pukul 10.00 dan 15.00 WITA dengan durasi latihan 10 menit.

3. Kuesioner Nordic Body Map digunakan untuk mengukur keluhan muskuloskeletal dengan 4 skala Likert.

4. Kuesioner 30 item of rating scale yang digunakan untuk mengukur tingkat kelelahan kerja penenun.

5. Kuesioner Neck Disability Index (NDI) (Vernon, 2007) yang digunakan untuk mengukur kemampuan fungsional leher.

6. Produktivitas kerja merupakan perbandingan dari luaran (output) dan masukan (input) per satuan waktu (time). Output berupa rerata hasil kerja (jumlah hasil tenun) kain yang dihasilkan perhari, input berupa skor dari keluhan muskuloskeletal yang diterima oleh tenaga kerja, dan satuan waktu adalah 8 jam kerja.

\section{Tempat dan Waktu Penelitian}

Penelitian ini dilakukan di industri tenun ikat endek "Sekar Jepun", Denpasar Timur, Kota Denpasar, Bali. Waktu penelitian ini dilaksanakan yaitu dari bulan Agustus 2017 - Maret 2018.

\section{HASIL PENELITIAN \\ Karakteristik Subjek Penelitian}


ISSN Print : 1411 -951 X, ISSN Online : 2503-1716

\section{Jurnal Ergonomi Indonesia}

(The Indonesian Journal of Ergonomic)

Vol 4., No.1 : 1 Januari - Juni 2018

Tabel 1 Data Karakteristik Subjek Penenun

Tenun Ikat

\begin{tabular}{ll}
\hline Variabel & Rerata \pm SB \\
\hline Umur (th) & $39,83 \pm 8,70$ \\
Berat Badan $(\mathrm{kg})$ & $51,83 \pm 3,53$ \\
Tinggi Badan $(\mathrm{cm})$ & $157,83 \pm 1,46$ \\
Indeks Massa Tubuh & $20,81 \pm 1,53$ \\
Pengalaman Kerja (th) & $18,33 \pm 8,59$ \\
\hline
\end{tabular}

Berdasarkan Tabel 1 diketahui rerata umur subjek dalam penelitian ini adalah $39,83 \pm 8,70$ tahun. Indeks massa tubuh dihitung berdasarkan perbandingan berat badan satuan kg dengan kuadrat dari tinggi badan dalam satuan meter pada subjek yang bersangkutan. Didapatkan rerata indeks massa tubuh subjek adalah $20,81 \pm 1,53$, rerata tersebut masuk dalam kategori ideal.

\section{Kondisi Lingkungan Penelitian}

Tabel 2 Kondisi Lingkungan Kerja

\begin{tabular}{|c|c|c|c|c|}
\hline \multirow{2}{*}{ Parameter } & Periode 1 & Periode 2 & \multirow{2}{*}{$\begin{array}{l}\text { Nilai } \\
p\end{array}$} & \multirow{2}{*}{ Ket. } \\
\hline & Rerata \pm SB & Rerata \pm SB & & \\
\hline $\begin{array}{l}\text { Suhu } \\
\text { Kering }\left({ }^{\circ} \mathrm{C}\right)\end{array}$ & & 65 & & TS \\
\hline $\begin{array}{l}\text { Suhu Basah } \\
\left({ }^{\circ} \mathrm{C}\right)\end{array}$ & 28,22 & 8 & 0,092 & $\mathrm{TS}$ \\
\hline $\begin{array}{l}\text { Kelembaban } \\
(\%) \\
\text { Intensitas }\end{array}$ & 67,44 & $67,11 \pm 1,708$ & 0,777 & $\mathrm{TS}$ \\
\hline Cahaya(lux) & $1010 \pm 14,10$ & $1002 \pm 22,86$ & 0,321 & TS \\
\hline & $83,43 \pm 2,626$ & $82,01 \pm 3,877$ & 0,611 & $\mathrm{TS}$ \\
\hline
\end{tabular}

\begin{tabular}{lllllll} 
Pre & 1,138 & & & 1,466 & & \\
MSDs & $46,91 \pm$ & & & $38,91 \pm$ & 0,006 & TN \\
Post & 0,792 & 0,018 & TN & 1,24 & & \\
Kelelah- & $33,91 \pm$ & & & $34,16 \pm$ & 0,010 & TN \\
an Pre & 0,9 & 0,006 & TN & 0,843 & & \\
Kelelah- & $49,75 \pm$ & & & $39,91 \pm$ & & \\
an Post & 1,356 & 0,237 & $\mathrm{~N}$ & 0,9 & 0,006 & $\mathrm{TN}$ \\
NDI & $24 \pm$ & & & $23,916 \pm$ & & \\
Pre & 0,852 & 0,012 & $\mathrm{TN}$ & 0,9 & 0,006 & $\mathrm{TN}$ \\
NDI & $24,25 \pm$ & & & $20,58 \pm$ & & \\
Post & 0,753 & 0,011 & $\mathrm{TN}$ & 0,9 & 0,015 & $\mathrm{TN}$ \\
$\begin{array}{l}\text { Produk- } \\
\text { tivitas }\end{array}$ & $0,02 \pm$ & & & $0,06 \pm$ & & \\
\hline
\end{tabular}

Pada Tabel 3 menunjukkan bahwa beberapa data seperti Keluhan muskuloskeletal pre Periode 1 maupun Periode 2 memiliki nilai $p>0,05$. Hal ini berarti bahwa data tersebut berdistribusi normal, sehingga dalam analisis uji beda dilakukan dengan uji parametrik t-paired. Sedangkan data lainnya seperti keluhan muskuloskeletal post Periode 1 dan Periode 2, data kelelahan pre Periode 1 dan Periode 2, data kelelahan post Periode2, data NDI pre dan post pada Periode 1 maupun Periode 2 dan data produktivitas Periode 1 dan Periode 2 setelah dilakukan uji Shapiro-Wilk test terlihat hasil bahwa data berdistribusi tidak normal (nilai $\mathrm{p}<0,05$ ), sehingga uji beda terhadap data tersebut dianalisis dengan uji non parametrik Wilcoxon test.

\section{Komparabilitas Data}

Tabel 4 Hasil Uji Komparabilitas Keluhan Muskuloskeletal,

Berdasarkan Tabel 2 dapat dilihat hasil uji kemaknaan suhu kering, suhu basah, kelembaban relatif, intensitas cahaya, dan kebisingan tidak mempunyai perbedaan yang signifikan antara Periode 1 dan Periode 2. Hal ini menunjukkan bahwa kedua Periode tersebut memiliki karakteristik lingkungan yang sama.

\begin{tabular}{|c|c|c|c|c|c|c|}
\hline \multirow[b]{2}{*}{ Periode } & \multicolumn{2}{|c|}{ MSDs Pre } & \multicolumn{2}{|c|}{ Kelelahan Pre } & \multicolumn{2}{|c|}{ NDI pre } \\
\hline & $\begin{array}{l}\text { Rerata } \\
\pm \mathrm{SB}\end{array}$ & $P$ & $\begin{array}{l}\text { Rerata } \\
\pm \mathrm{SB}\end{array}$ & $P$ & $\begin{array}{l}\text { Rerata } \\
\pm \text { SB }\end{array}$ & $P$ \\
\hline Periode & $31,25 \pm$ & & $33,91 \pm$ & & $24 \pm$ & \\
\hline 1 & 1,138 & $0881^{\mathrm{a}}$ & 0,9 & $0564^{\mathrm{b}}$ & 0,852 & $077^{b}$ \\
\hline Periode & $31,16 \pm$ & $0,881^{a}$ & $34,16 \pm$ & $0,564^{\circ}$ & $23,92 \pm$ & $0,17^{\circ}$ \\
\hline 2 & 1,466 & & 0,83 & & 0,9 & \\
\hline
\end{tabular}

$\mathrm{a}=t$-paired

$\mathrm{b}=$ Wilcoxon

Normalitas Data

Tabel 3 Hasil Uji Normalitas Data Keluhan Muskuloskeletadiuraikan bahwa tidak ada perbedaan yang Kelelahan, NDI, dan Produktivitas

\begin{tabular}{llllllll}
\hline \multirow{2}{*}{$\begin{array}{l}\text { Varia- } \\
\text { bel }\end{array}$} & \multicolumn{2}{l}{ Periode 1} & & \multicolumn{2}{l}{ Periode 2} & \\
\cline { 2 - 3 } & $\begin{array}{l}\text { Rerata } \\
\text { SB }\end{array}$ & $\begin{array}{l}\text { Nilai } \\
p\end{array}$ & Ket. & $\begin{array}{l}\text { Rerata } \pm \\
\text { SB }\end{array}$ & $\begin{array}{l}\text { Nilai } \\
p\end{array}$ & \\
\hline MSDs & $31,25 \pm$ & 0,064 & N & $31,16 \pm$ & 0,197 & N
\end{tabular}
bermakna antara data pre Periode 1 dan Periode $2(p>0,05)$. Hal ini berarti bahwa tidak ada efek kondisi sebelumnya pada Periode 1 yang mempengaruhi perubahan pada variabel terikat. Selain itu, washing 


\section{Jurnal Ergonomi Indonesia}

\section{(The Indonesian Journal of Ergonomic)}

out period cukup memberi efek pengembalian ke kondisi awal seperti pada kondisi pre Periode 1. Dengan demikian maka efek intervensi terjadi murni karena adanya perlakukan.

\section{Efek Perlakuan}

Tabel 5 Hasil Uji Efek Perlakuan Menggunakan Uji t-paired dan Wilcoxon

\begin{tabular}{llll}
\hline \multirow{2}{*}{ Variabel } & Periode 1 & Periode 2 & Nilai \\
\cline { 2 - 3 } & Rerata \pm SB & Rerata \pm SB & $P$ \\
\hline MSDs Pre & $31,25 \pm 1,138$ & $31,16 \pm 1,466$ & $0,881^{\mathrm{a}}$ \\
MSDs Post & $46,91 \pm 0,792$ & $38,91 \pm 1,24$ & $0,002^{\mathrm{b}}$ \\
Selisih MSDs & $15,66 \pm 1,435$ & $7,75 \pm 1,959$ & $0,001^{\mathrm{a}}$ \\
\hline Kelelahan Pre & $33,91 \pm 0,9$ & $34,16 \pm 0,83$ & $0,564^{\mathrm{b}}$ \\
Kelelahan & $49,75 \pm 1,356$ & $39,91 \pm 0,9$ & $0,002^{\mathrm{b}}$ \\
Post & & & \\
Selisih & $15,83 \pm 1,33$ & $5,75 \pm 0,452$ & $0,002^{\mathrm{b}}$ \\
\hline Kelelahan & $24 \pm 0,852$ & $23,92 \pm 0,9$ & $0,77^{\mathrm{b}}$ \\
\hline NDI Pre & $24,25 \pm 0,753$ & $20,58 \pm 0,9$ & $0,002^{\mathrm{b}}$ \\
NDI Post & $0,416 \pm 0,514$ & $3,33 \pm 0,651$ & $0,002^{\mathrm{b}}$ \\
\hline Selisih NDI & $0,02 \pm 0,004$ & $0,06 \pm 0,0127$ & $0,002^{\mathrm{b}}$ \\
\hline Produktivitas & & & \\
\hline
\end{tabular}

$\mathrm{a}=t$-paired

$\mathrm{b}=$ wilcoxon

Hasil uji beda seperti yang tampak pada Tabel 5 menunjukkan bahwa keluhan muskuloskeletal sebelum bekerja (pre) pada Periode 1 dan 2 tidak berbeda secara bermakna $(p>0,05)$ dengan rerata $31,25 \pm 1,13$ pada Periode 1 dan $31,16 \pm 1,46$ pada Periode 2. Penurunan keluhan muskuloskeletal terjadi pada kondisi akhir atau setelah bekerja (post) bahwa rerata keluhan muskuloskeletal pada Periode 1 46,91 $\pm 0,79$ sedangkan rerata keluhan muskuloskeletal pada Periode 2 $38,91 \pm 1,24$. Hal ini menunjukkan adanya penurunan sebesar $17,05 \%$ dan perbedaan ini dikatakan bermakna $(p>0,05)$. Sehingga dapat disimpulkan bahwa penurunan keluhan muskuloskeletal semata-mata disebabkan karena adanya intervensi yang diberikan.

Pada Periode 1 Keluhan muskuloskeletal terbesar pada area otot leher bawah sebesar 83,33\%, bahu kanan dan bahu kiri sebesar $66,67 \%$ dan punggung atas sebesar $41,67 \%$. Sedangkan pada Periode 2 keluhan muskuloskeletal mengalami penurunan, didapatkan persentase pada area otot leher bawah sebesar 41,67\%, bahu kanan dan bahu kiri sebesar $25 \%$ dan punggung atas sebesar $41,67 \%$.

Besarnya keluhan muskuloskeletal pada Periode 1 disebabkan adanya pembebanan pada leher bawah, bahu dan punggung atas karena posisi menenun dengan posisi duduk selama 8 jam, bahu yang sedikit terangkat, kepala menunduk dan lengan mendorong dan menarik secara berulang tanpa adanya istirahat aktif sehingga mempengaruhi otot-otot lengan dan bahu yang pada akhirnya menimbulkan keluhan muskuloskeletal. Sejalan dengan penelitian Titin dkk. (2012) keluhan muskuloskeletal yang dialami oleh pembatik tulis disebabkan karena aktivitas berulang-ulang yang dilakukan oleh pembatik, sehingga otot-otot menerima tekanan akibat beban kerja secara terus menerus tanpa memperoleh kesempatan relaksasi, faktor penyebab lainnya juga disebabkan oleh sikap dan postur kerja yang tidak alamiah.

Posisi duduk statis disertai dengan sikap tubuh yang tidak ergonomis saat bekerja menyebabkan adanya penekanan pada bagian otot tubuh tertentu yang menyebabkan terganggunya sirkulasi darah di dalam tubuh dan berkurangnya pasokan oksigen (O2) sehingga terjadinya penumpukan asam laktat di dalam otot. Pekerjaan menenun dengan sikap kerja duduk disertai adanya gerakan berulang, dan sikap kerja yang tidak alamiah menyebabkan adanya reaksi berupa keluhan pada sistem otot skeletal (Manuaba, 1992).

Dilihat dari analisis waktu gerakan (time motion study) yang bertujuan untuk mengetahui gerakan efektif dan tidak efektif saat proses menenun didapatkan data saat menenun pada Periode 1 pekerja melakukan gerakan tidak efektif \pm 5 kali perjam, sedangkan pada Periode 2 gerakan tidak efektif sebanyak \pm 3 kali perjam. 


\section{Jurnal Ergonomi Indonesia}

\section{(The Indonesian Journal of Ergonomic)}

Gerakan-gerakan tidak efektif yang dimaksud berupa berbincang-bincang antar pekerja, menggaruk kepala, dan menyeka keringat.

Penelitian yang dilakukan oleh Nurhayati (2013), tentang Prinsip latihan stabilisasi, menunjukkan bahwa Program latihan stabilisasi yang bertujuan untuk mengontrol posisi dari alignment servikal agar tetap pada posisi yang fisiologis dan juga menjaga postur tulang leher dalam posisi yang aman dan mencegah terjadinya cedera berulang.

Latihan stabilisasi melalui latihan aktif ini juga dapat membuat pembuluh darah sekitar mengalami vasodilatasi dan menyebabkan aliran darah lokal yang akan diikuti dengan meningkatnya suplai oksigen ke jaringan sehingga dapat mengurangi ketegangan pada otot dan fleksibilitas otot akan meningkat.

Dengan demikian, dapat dikatakan bahwa penerapan cervical stabilization melalui active exercise yang dilakukan setiap 2 jam setelah bekerja dapat mengurangi keluhan muskuloskeletal.

Kemudian, analisis uji komparabilitas terhadap kelelahan sebelum bekerja antara Periode 1 dan Periode 2 adalah tidak berbeda secara bermakna $(p>0,05)$. Sedangkan kondisi setelah bekerja pada Periode 1 dan Periode 2 terdapat perbedaan, rerata skor pada Periode 1 adalah 49,75 $\pm 1,35$ dan pada Periode 2 adalah $39,91 \pm 0,90$ atau mengalami penurunan sebesar 19,78\%. Ini berarti bahwa dengan adanya perlakuan dapat menurunkan kelelahan penenun secara signifikan.

Kelelahan terbesar didapatkan pada kategori kelelahan fisik, penurunan kelelahan ini terjadi karena antara Periode 1 dan 2 ada perbedaan cara kerja yaitu adanya istirahat aktif yang dilakukan setiap 2 jam setelah bekerja, istirahat aktif berupa latihan aktif berupa cervical stabilization yang dilakukan setiap 2 jam setelah bekerja agar tidak terjadi akumulasi kelelahan dan otot-otot anggota gerak sehingga dapat bekerja secara aktif. Sesuai dengan penelitian Adiputra (2003) dinyatakan bahwa kelelahan yang terjadi pada pekerja karena organ tubuh secara terus menerus menerima beban kerja eksternal tanpa adanya kesempatan istirahat atau mendapat beban kerja yang melewati kapasitasnya. Selain itu, Sutjana (2008) juga menyatakan istirahat pendek setiap 2 jam kerja selama 5-10 menit maka kesiapan kerja tetap di atas ambang. Selain itu, penelitian yang dilakukan Purnawan (2002) perbaikan stasiun kerja dan pemberian istirahat aktif perajin keramik mengurangi keluhan subjektif sebesar 78\%. Kemudian, analisis uji komparabilitas terhadap kemampuan fungsional berdasarkan rerata skor NDI pre pada Periode 1 dan Periode 2 adalah tidak berbeda secara bermakna $(p>0,05)$. Sedangkan skor NDI post pada Periode 1 dan Periode 2 terdapat perbedaan, rerata skor NDI pada Periode 1 adalah 24,25 $\pm 0,75$ dan pada Periode 2 adalah 20,58 $\pm 0,90$ atau mengalami peningkatan NDI sebesar $15,13 \%$. Ini berarti bahwa dengan adanya perlakuan dapat meningkatkan kemampuan fungsional penenun secara signifikan.

Berdasarkan penelitian Dusuncelli dkk. (2009) dinyatakan bahwa neck stabilization exercise efektif dalam menangani pasien dengan keluhan nyeri leher serta dapat meningkatkan kemampuan fungsional pasien ataupun memungkinkan mereka untuk kembali ke aktifitas normal. Dalam penelitian Ferreira (2006) dilaporkan bahwa latihan stabilisasi efektif dalam menurunkan nyeri leher kronik dan meningkatkan fungsi dari servikal.

Selain itu, Rerata produktivitas pada Periode 1 sebesar $0,02 \pm 0,004$ dan rerata produktivitas pada Periode 2 adalah $0,06 \pm 0,0127$ atau mengalami peningkatan sebesar $66,67 \%$. Hal ini menunjukkan bahwa penerapan cervical stabilization melalui active exercise meningkatkan kemampuan fungsional dan produktivitas kerja penenun endek di industri tenun ikat Denpasar.

Peningkatan produktivitas kerja pada Periode 2 disebabkan karena adanya penerapan cervical stabilization melalui active exercise setiap 2 jam bekerja selama 


\section{Jurnal Ergonomi Indonesia}

\section{(The Indonesian Journal of Ergonomic)}

10 menit. Didukung oleh penelitian Rohana (2012) kenaikan produktivitas pada operator computer yang diberikan intervensi yang meliputi perbaikan postur atau sikap kerja, pemberian waktu istirahat pendek selama 15 menit setiap dua jam setelah bekerja dapat menurunkan kelelahan otot tanpa mengurangi produktivitas. Keluhan muskuloskeletal dan kelelahan kerja serta kemampuan fungsional dapat meningkatkan efisiensi waktu kerja dan produktivitas kerja penenun.

\section{SIMPULAN DAN SARAN Simpulan}

Berdasarkan hasil analisis dan pembahasan yang telah dijabarkan sebelumnya, dapat disimpulkan bahwa.

1. Penerapan cervical stabilization melalui active exercise meningkatkan kemampuan fungsional dilihat dari penurunan keluhan muskuloskeletal sebesar $17,05 \%$

2. Penerapan cervical stabilization melalui active exercise meningkatkan kemampuan fungsional dilihat dari penurunan kelelahan kerja sebesar $19,78 \%$

3. Penerapan cervical stabilization melalui active exercise meningkatkan kemampuan fungsional dilihat dari peningkatan neck disability index sebesar $15,13 \%$

4. Penerapan cervical stabilization melalui active exercise meningkatkan produktivitas kerja sebesar $66,67 \%$

\section{Saran}

Berdasarkan simpulan di atas maka dapat disarankan beberapa hal sebagai berikut.

1. Penelitian berikutnya diharapkan tidak hanya melakukan pengukuran subjektif namun juga pengukuran yang bersifat objektif.

2. Penerapan cervical stabilization melalui active exercise disarankan untuk dapat dilakukan setiap 2 jam setelah bekerja pada industri tenun ikat (endek), agar dapat meminimalkan keluhan yang
Vol 4., No.1 : 1 Januari - Juni 2018

ditimbulkan akibat proses kerja menenun yang akan menyebabkan terjadinya penurunan kemampuan fungsional leher dan menghambat aktivitas sehari-hari.

3. Kepada pemilik industri tenun ikat (endek) "Bali Sekar Jepun" agar memasang peredam suara untuk mengatasi kebisingan pada proses menenun.

\section{DAFTAR PUSTAKA}

Adiputra, I. N. 2003. Kapasitas Kerja Fisik Orang Bali. Majalah Kedokteran Udayana (Udayana Medical Journal). 34 (1204) p; 108 -110

Adnyani, I. A. 2013.'Implementasi Desain Alat Pemidangan Memakai Mikrokontroler Berbasis Ergonomi Meningkatkan Kinerja Perajin Midang Kain Tenun Endek di Kecamatan Blahbatuh Gianyar" (Disertasi). Denpasar: Universitas Udayana.

Dusunceli, Y. Ozturk, C. Atamaz, F. Hepguler, S. Durmaz, B. 2009. Efficiacy Of Neck Stabilization Exercises for Neck Pain : A Randomized Controlled Study. Journal of Rehabilitation Information.41:626-631

Ferreira, P.H. Ferreira, M.L. Maher, C.G. Herbert, R.D. Refshauge, K. (2006). Specific stabilization Exercise for spinal and pelvic pain : a systematic review.Aust J Physiother.52(2)

Kadarusman, A. dan Rachmat, A. 2002. Fatigue Design dan Relokasi waktu Istirahat. Majalah Kedokteran Udayana (Udayana Medical Journal), 33(116,4);129-135

Kaka, B. Ogwumike, O.O. Ogunlade, O.S. Adeniyi, F.A. (2015). Effect Of Neck Stabilization and Dynamic exercises on pain,disability, and fear avoidance beliefs in patients with non-specific neck pain ; a randomized clinical trial. Arch Physiother Glob Res.19(3):17-29

Kisner, C. dan Colby, L.A. 2012. Therapeutic Exercise Foundations 
ISSN Print : 1411 -951 X, ISSN Online : 2503-1716

\section{Jurnal Ergonomi Indonesia}

(The Indonesian Journal of Ergonomic)

Vol 4., No.1 : 1 Januari - Juni 2018

and Techniques $6^{\text {th }}$ Edition. F.A Davis Company: Philadelphia

Manuaba, A. 1992. Pengaruh Ergonomi Terhadap Produktivitas. Bunga Rampai Ergonomi Vol. 1. Program Studi Ergonomi - Fisiologi Kerja. Denpasar: Universitas Udayana.

Manuaba, A. 2006. A Total Approach in Ergonomics is A Must to Attain Human, Competitive and Sustainable Work System and Products. Dipresentasikan pada: Ergo Future 2006: International Symposium on Past, Present and Future Ergonomics, Occupational Safety and Health. Denpasar 2830th August

Nurhayati I.R. 2013. "Penambahan Cervical Stabilization Exercise pada Contract Relax Stretching lebih baik dalam menurunkan disabilitas leher akibat myalgia pada bekerja posisi statis" (Skripsi). Jakarta: Universitas Esa Unggul.

Purnawan, I.B. 2002. Perbaikan Stasiun Kerja dan Pemberian Istirahat Aktif Mengurangi Keluhan Subjektif dan Meningkatkan Produktivitas Kerja Wanita Perajin Keramik di Desa Pejaten Kediri Tabanan Bali. Program Studi Disain, Program Studi Seni Rupa dan Disain Universitas Udayana. Kongres Nasional XI Seminar Ilmiah XIII International Seminar on Ergonomics and Sport Physiology (KONAS IAIFI).

Rohana, S.N. 2012. Analisis Kelelahan Pekerja pada Perkampungan Industri Kecil Penggilingan Cakung Jakarta Timur. Seminar Nasional Ergonomi Universitas Widyatama Bandung 13-14 November 2012.

Sutjana, I.D.P. 2008. Kecelakaan Kerja di Bali Dilihat Dari Waktu Kejadian Kecelakaan Tahun 1995-1998. (Cited: 2016 May 04). Available From: 